\title{
Predictive Control of Vehicle ISD Suspension Based on a Hydraulic Electric Inerter
}

\author{
Yanling Liu $\mathbb{D},{ }^{1}$ Wentao Zhao $\mathbb{D},{ }^{1}$ Xiaofeng Yang $\left(\mathbb{D},{ }^{1}\right.$ Long Chen $\mathbb{D}^{2},{ }^{2}$ and Yujie Shen ${ }^{2}$ \\ ${ }^{1}$ School of Automotive and Traffic Engineering, Jiangsu University, Zhenjiang 212013, China \\ ${ }^{2}$ Automotive Engineering Research Institute, Jiangsu University, Zhenjiang 212013, China \\ Correspondence should be addressed to Xiaofeng Yang; yangxf18@ujs.edu.cn
}

Received 3 January 2019; Revised 19 March 2019; Accepted 7 May 2019; Published 15 September 2019

Academic Editor: Francesco Braghin

Copyright (c) 2019 Yanling Liu et al. This is an open access article distributed under the Creative Commons Attribution License, which permits unrestricted use, distribution, and reproduction in any medium, provided the original work is properly cited.

As a two-terminal mechanical element, the inerter has been successfully applied in various mechanical fields, such as automotive engineering and civil engineering, for passive control and semiactive control. In this paper, a hydraulic electric inerter is considered an active device to suppress the vibration of a vehicle suspension system. The components and working principle of the hydraulic electric inerter are first introduced. On the basis of a force test of the hydraulic electric inerter, nonlinear factors such as friction, the damping force, and the elastic effect are analyzed, and parameter identification methods are adopted to identify the detailed parameters. A dynamic model of the vehicle suspension system employing a nonlinear hydraulic electric inerter is established, and the predictive controller is designed to further improve the vibration isolation performance of the suspension system. Numerical simulations show that the performance of the vehicle ISD (inerter-spring-damper) suspension system is significantly improved compared to the passive suspension. Finally, bench tests are carried out, and the advantages of vehicle ISD suspension are demonstrated. The RMS (root-mean-square) value of the vehicle body acceleration and the RMS value of the suspension working space are reduced by $16.1 \%$ and $8.9 \%$, respectively.

\section{Introduction}

A vehicle suspension system is a general device between the wheel and body of a vehicle that not only suppresses vibrations but also supports the vehicle body mass [1]. However, the "spring-damper" structure of traditional passive vehicle suspension systems limits improvements of the vibration isolation performance of the suspension system due to lack of mass impedance. In 2002, an inerter [2] was first proposed by Professor Smith at Cambridge University, and as a two-terminal element, it has been widely employed in vehicle engineering [3-6], civil engineering $[7,8]$, train suspension $[9,10]$, wind turbines $[11]$, and structural vibration $[12,13]$. The inerter has been realized in many forms, such as a ball-screw inerter [14], rack and pinion inerter [15], hydraulic inerter [16], and mechatronic inerter [17]. In vehicle suspension fields, for the design of a passive suspension system using the "inerter, spring, and damper" network structure, Smith first analyzed several common forms of vehicle suspension systems using an inerter and found that their vibration isolation performance can be effectively improved [18]. In [19], a control method based on matrix inequality was applied to vehicle suspension and proved that these structures have better performance. In [20], by considering the constraints of the suspension working space, the ride comfort and tire grip performance of suspension employing an inerter element could be significantly improved. In [21], an improved design of a dynamic vibration absorber was proposed and applied to vehicle suspension systems, and the results showed that the damping performance of the new vehicle ISD suspension was effectively improved.

More recently, a semiactive suspension and a semiactive inerter $[22,23]$ were proposed to further improve performance. In [24], a semiactive suspension with an inerter was developed and its improved performance advantage was proven by comparison with passive ISD suspension. In [25], a state feedback $\mathrm{H}_{2}$ controller was designed, which showed 
that suspension with an adaptive inerter could improve ride quality and tire deflection. In [26], a force-tracking design method for a semiactive damper and semiactive inerter was proposed. A semiactive suspension with a semiactive inerter and semiactive damper can better track the target active control force. This demonstrated the necessity and benefit of introducing a semiactive inerter into vehicle suspension.

However, with the proposed mechatronic inerter introduced in [17], a PMEM (permanent magnetic electric machine) can also be used as an active force device to control the output force of the mechatronic inerter. This paper explores a new vehicle suspension system employing a hydraulic electric inerter. Predictive control is used to regulate the vehicle suspension to improve performance on the basis of a nonlinear model of the inerter device. This paper is organized as follows.

In Section 2, a hydraulic electric inerter is designed and the working principle is introduced. Force tests are completed to demonstrate the nonlinear model in Section 3. A dynamic model of the suspension system involving the nonlinear hydraulic electric inerter is established and a predictive controller is designed to improve the vibration isolation performance in Section 4. In Section 5, experiments on vehicle ISD suspension using the hydraulic electric inerter are conducted and the results are discussed in detail. Finally, some conclusions are drawn in Section 6.

\section{Design of the Hydraulic Electric Inerter}

In this paper, a new form of inerter that involves a hydraulic inerter and a linear motor is considered. The new type of inerter includes two hydraulic piston mechanisms and a permanent magnet synchronous linear motor. This new type of inerter can be called the hydraulic electric inerter. Its structure is indicated in Figure 1, and Figure 2 shows the prototype diagram of the hydraulic electric inerter.

As shown in the figures above, the deputy piston rod is connected with the mover of the linear motor, and the stator of the linear motor is uniformly distributed with windings, which are consolidated with the deputy cylinder. The working principle of the hydraulic electric inerter is that the main cylinder and the main piston rod move relatively as two free endpoints, the deputy piston rod and the mover axis move through the oil, the mover shaft and the windings in the motor stator generate relative motion in the motor working chamber, and then the linear motor is connected with the external circuit to generate the induction electromotive force. The existence of the linear motor can adjust the output force of the whole device.

The main parameters of the hydraulic electric inerter are shown in Table 1.

The inertance is an important physical parameter in this paper. From the working principle of the hydraulic cylinder,

$$
\left(v_{2}-v_{1}\right) S_{\mathrm{R}}=\left(v_{a}-v_{1}\right) S_{\mathrm{r}}
$$

where $S_{\mathrm{R}}$ represents the piston area of the main hydraulic cylinder; $S_{\mathrm{r}}$ represents the piston area of the deputy hydraulic cylinder; $v_{1}$ and $v_{2}$ are the speed of the cylinder block and piston rod of the main hydraulic cylinder, respectively; and $v_{a}$ represents the speed of the mover axis.

From the law of conservation of energy,

$$
F\left(v_{2}-v_{1}\right)=m \dot{v}_{a}\left(v_{a}-v_{1}\right),
$$

where $F$ represents the force between the piston rod and the cylinder block of the main hydraulic cylinder, $m$ represents the mass of the mover axis and deputy piston rod, and $\dot{v}_{a}$ represents the acceleration of the mover axis.

Taking the derivative of formula (1) and substituting it into formula (2),

$$
F=m \frac{S_{\mathrm{R}}}{S_{\mathrm{r}}}\left[\frac{S_{\mathrm{R}}}{S_{\mathrm{r}}}\left(\dot{v}_{2}-\dot{v}_{1}\right)+\dot{v}_{1}\right] .
$$

Formula (3) can be approximately expressed as

$$
F=m\left(\frac{S_{\mathrm{R}}}{S_{\mathrm{r}}}\right)^{2}\left(\dot{v}_{2}-\dot{v}_{1}\right) \text {. }
$$

The inertance is as follows:

$$
b=\left(\frac{S_{\mathrm{R}}}{S_{\mathrm{r}}}\right)^{2} m
$$

\section{Force Test and Parameter Identification of the Hydraulic Electric Inerter}

3.1. Force Test of the Hydraulic Electric Inerter. A force test of the hydraulic electric inerter is carried out with the INSTRON 8800 hydraulic servo vibration platform. The displacement can be controlled, and the force between the devices can be recorded by a force sensor. Different excitation frequencies are considered in the force test, the input used in the test is shown in Table 2, and the frequency response trends of the hydraulic electric inerter are shown in Figures 3 and 4.

From Figure 3, it is clear that the actual amplitude of the prototype has a definite deviation from the theoretical value at low frequencies $(0 \mathrm{~Hz} \sim 2 \mathrm{~Hz})$ and high frequencies $(5 \mathrm{~Hz} \sim 10 \mathrm{~Hz})$. In the middle-frequency region $(2 \mathrm{~Hz} \sim 5 \mathrm{~Hz})$, the result is basically consistent with the theoretical value. From Figure 4, it is seen that the phase of the prototype fluctuates around the theoretical phase over the entire frequency range, which is due to the interference of nonlinear factors in the test prototype.

Generally, in the low-frequency stage, friction is the main factor because the velocity and acceleration at the two ends of the inerter are small, while in the high-frequency stage, parasitic damping and the oil elastic effect become the main nonlinear factors.

\subsection{Parameter Identification of the Hydraulic Electric Inerter.} The nonlinear factors affecting the hydraulic electric inerter can be classified into friction, parasitic damping, and oil elasticity. Combining the mechanical analysis and the influence of the nonlinear factors, a nonlinear mechanical model of the hydraulic electric inerter can be obtained, as shown in Figure 5. 


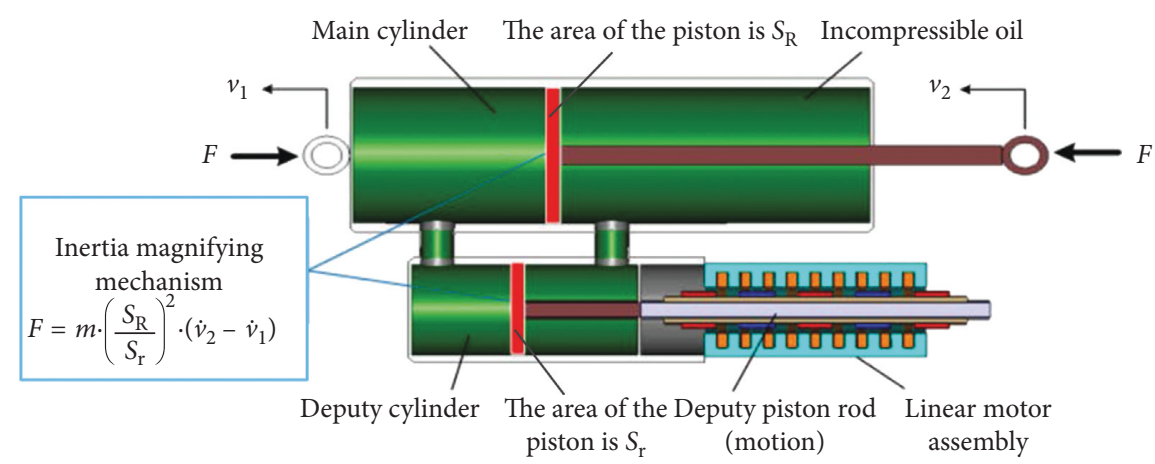

FIGURE 1: Structure diagram of the hydraulic electric inerter.

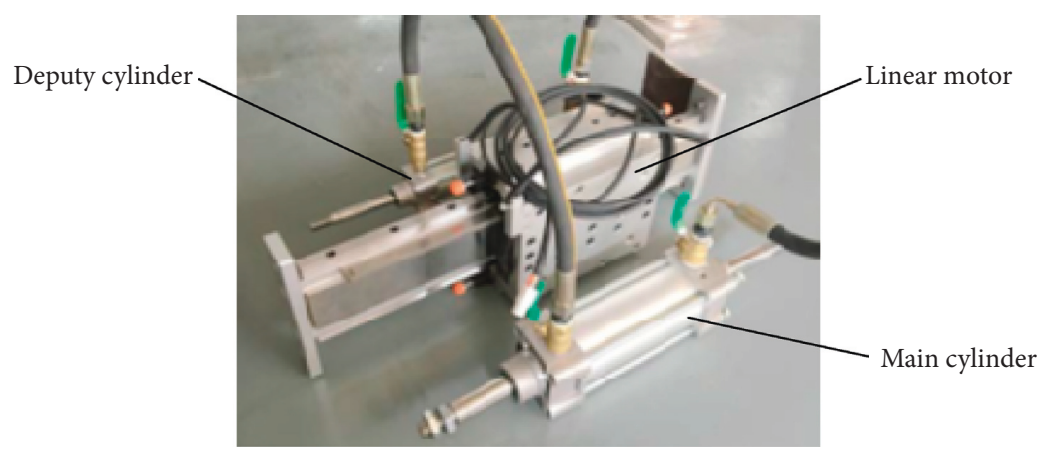

Figure 2: Prototype diagram of the hydraulic electric inerter.

TABLe 1: Parameter information of the hydraulic electric inerter.

\begin{tabular}{lc}
\hline Name & Value \\
\hline Main cylinder inner diameter $(\mathrm{mm})$ & 63 \\
Main piston rod diameter $(\mathrm{mm})$ & 20 \\
Deputy cylinder inner diameter $(\mathrm{mm})$ & 32 \\
Diameter of the deputy piston rod $(\mathrm{mm})$ & 12 \\
Motor mover mass $(\mathrm{kg})$ & 5.6 \\
Main cylinder stroke $(\mathrm{mm})$ & \pm 50 \\
Deputy cylinder stroke $(\mathrm{mm})$ & \pm 100 \\
Peak current $(\mathrm{A})$ & 10 \\
Rated current $(\mathrm{A})$ & 5 \\
Internal resistance of the linear motor $(\Omega)$ & 3.8 \\
Linear motor inductor $(\mathrm{mH})$ & 26 \\
\hline
\end{tabular}

TABle 2: Test input parameters.

\begin{tabular}{lcc}
\hline Displacement input & Parameters & Values \\
\hline \multirow{3}{*}{$x=A \cos (\omega t+\theta)$} & Frequency $\omega(\mathrm{Hz})$ & $(0.1,10)$ \\
& Amplitude $A(\mathrm{~mm})$ & 10 \\
& Initial phase $\theta(\mathrm{rad})$ & 0 \\
\hline
\end{tabular}

According to Figure 5, the output force $F_{\mathrm{R}}$ of a pair of hydraulic cylinders can be calculated by the inertia force, the elastic force $F_{\mathrm{k}}$, the damping force $F_{\mathrm{d}}$, and friction $F_{\mathrm{f}}$. The output force $F_{\mathrm{R}}$ can eventually be expressed by the following formula:

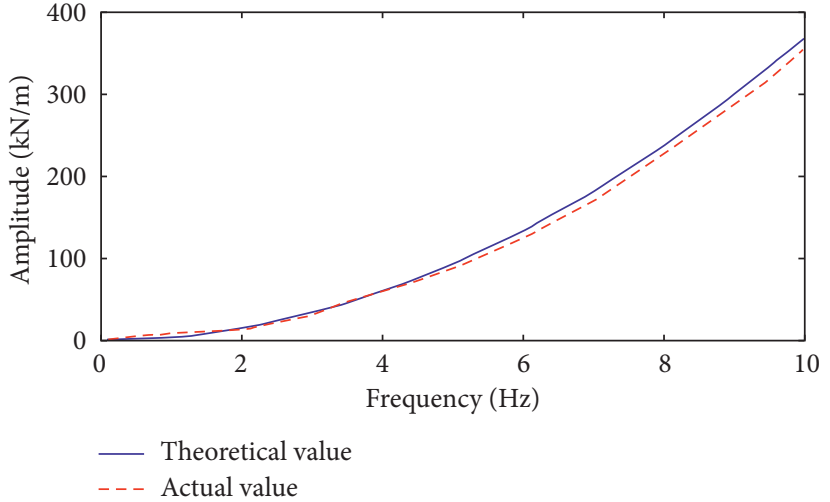

Figure 3: Amplitude-frequency characteristic of the hydraulic electric inerter.

$$
\begin{aligned}
F_{\mathrm{R}}= & b\left(\ddot{x}_{1}-\ddot{x}_{2}\right)+f \operatorname{sgn}\left(\dot{x}_{1}-\dot{x}_{2}\right)+k_{\mathrm{e}}\left(x_{1}-x_{2}\right) \\
& +c_{\mathrm{e}}\left(\dot{x}_{1}-\dot{x}_{2}\right)+F_{1},
\end{aligned}
$$

where $f$ represents the amplitude of the nonlinear friction force, $x_{1}$ represents the displacement of the bottom end of the main cylinder, $x_{2}$ represents the displacement of the upper end of the main cylinder, sgn represents the sign function, $k_{\mathrm{e}}$ represents the equivalent stiffness coefficient of the oil elasticity, $c_{\mathrm{e}}$ represents the equivalent damping coefficient of the parasitic damper, $F_{1}$ represents the thrust of the linear motor, and at this point, $F_{1}=0$. 


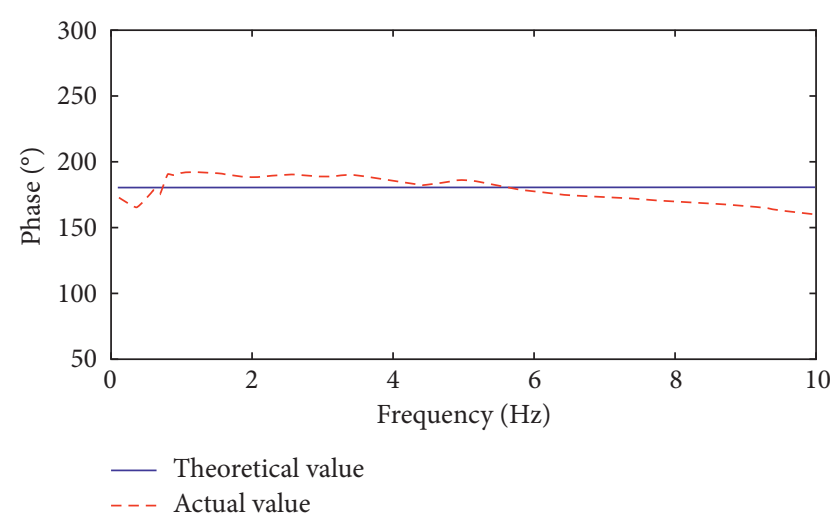

FIgURE 4: Phase-frequency characteristic of the hydraulic electric inerter.

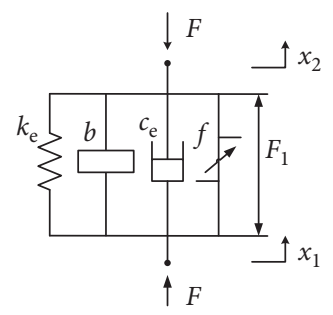

FIgURE 5: Nonlinear mechanical model of the hydraulic electric inerter.

Setting the vibration frequency to $0.1 \mathrm{~Hz}$ and using a triangle wave as the input signal, the hydraulic piston performs uniform motion and reciprocates back and forth every 10 seconds. The speed and acceleration of the hydraulic piston are close to 0 . The damping force and the inerter force are equal to 0 . That is, when the vibration frequency is $0.1 \mathrm{~Hz}$, friction plays a dominant role among the nonlinear factors.

It can be clearly seen from Figure 6 that when the vibration frequency is set at $0.1 \mathrm{~Hz}$, the response curve exhibits square wave characteristics. This property is consistent with the nature of nonlinear friction in formula (6). According to Figure 6, the magnitude of nonlinear friction can be estimated to be $0.5 \mathrm{kN}$.

Therefore, the nonlinear identification parameters are reduced to two parts: the equivalent damping coefficient $c_{\mathrm{e}}$ and the equivalent stiffness coefficient $k_{\mathrm{e}}$. A parameter identification model is established in Simulink, and the related parameters of the identification algorithm are shown in Table 3. The optimization objective function to obtain a minimum value is shown in the following formula:

$$
J(\theta)_{\min }=\sqrt{\frac{\sum_{n=1}^{N}\left|F_{\mathrm{r}}(n)-F_{\mathrm{s}}(n)\right|^{2}}{N}},
$$

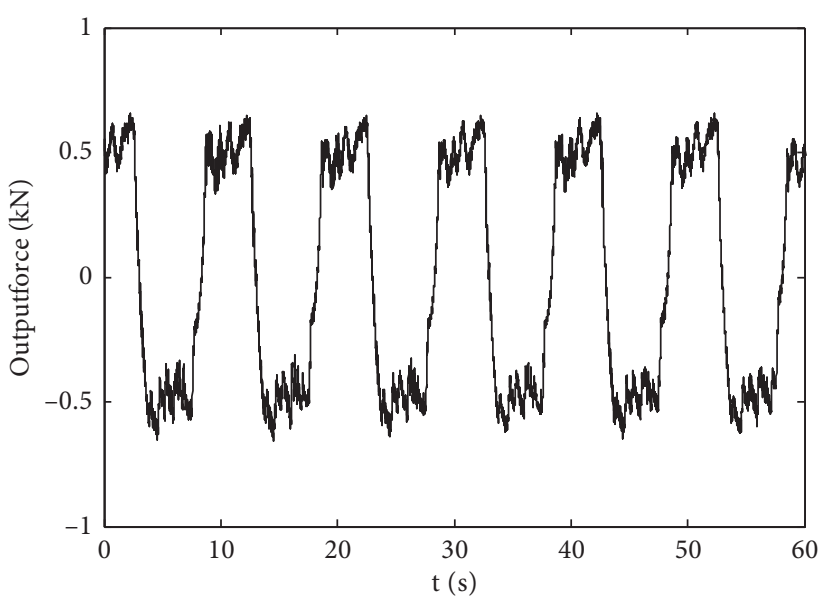

Figure 6: Force output curve at $0.1 \mathrm{~Hz}$ frequency.

TABLE 3: Correlation settings of the parameter identification algorithm.

\begin{tabular}{lc}
\hline Setting objects & Setting results \\
\hline Identification algorithm & Trust region reflective \\
Optimization method & Nonlinear least squares \\
Parameter cutoff error & 0.01 \\
Function cutoff error & 0.01 \\
\hline
\end{tabular}

TABle 4: Parameter identification results.

\begin{tabular}{lc}
\hline Parameters & $\begin{array}{c}\text { Identification } \\
\text { results }\end{array}$ \\
\hline Equivalent stiffness coefficient $k_{\mathrm{e}}\left(\mathrm{kN} \cdot \mathrm{m}^{-1}\right)$ & 709 \\
Equivalent damping coefficient $c_{\mathrm{e}}\left(\mathrm{N} \cdot \mathrm{S} \cdot \mathrm{m}^{-1}\right)$ & 1293 \\
\hline
\end{tabular}

where $\theta$ represents the set of parameters to be identified, $F_{\mathrm{r}}(n)$ represents the force calculated, and $F_{\mathrm{s}}(n)$ represents the testing force.

The input test data of $2 \mathrm{~Hz}, 4 \mathrm{~Hz}, 6 \mathrm{~Hz}, 8 \mathrm{~Hz}$, and $10 \mathrm{~Hz}$ sinusoidal excitation frequencies are used as samples, and the final identification results of the parameters equivalent damping coefficient $c_{\mathrm{e}}$ and equivalent stiffness coefficient $k_{\mathrm{e}}$ are shown in Table 4.

Inserting the amplitude of the nonlinear friction force $f$, the equivalent damping coefficient $c_{\mathrm{e}}$, and the equivalent stiffness coefficient $k_{\mathrm{e}}$ into formula (1) and verifying the simulation, a comparison between the simulation results and experimental results is shown in Figure 7.

The relationships between force and displacement and between force and velocity are shown in Figure 7 . The results show that the nonlinear mechanical model of the pair of hydraulic cylinders including friction, parasitic damping, and oil elasticity is accurate, the method of identifying the nonlinear parameters is effective, and the identified parameters are reliable. 


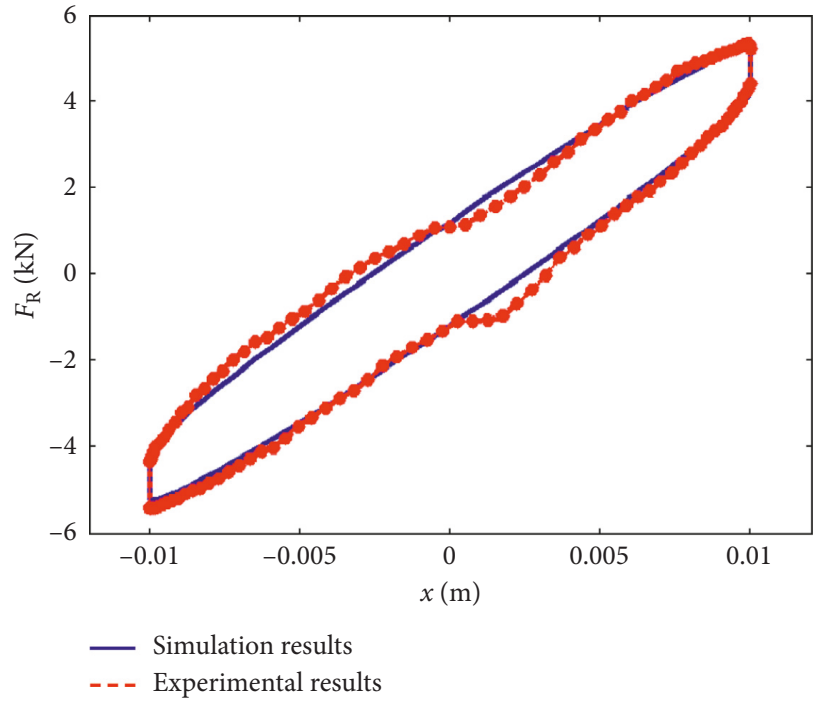

(a)

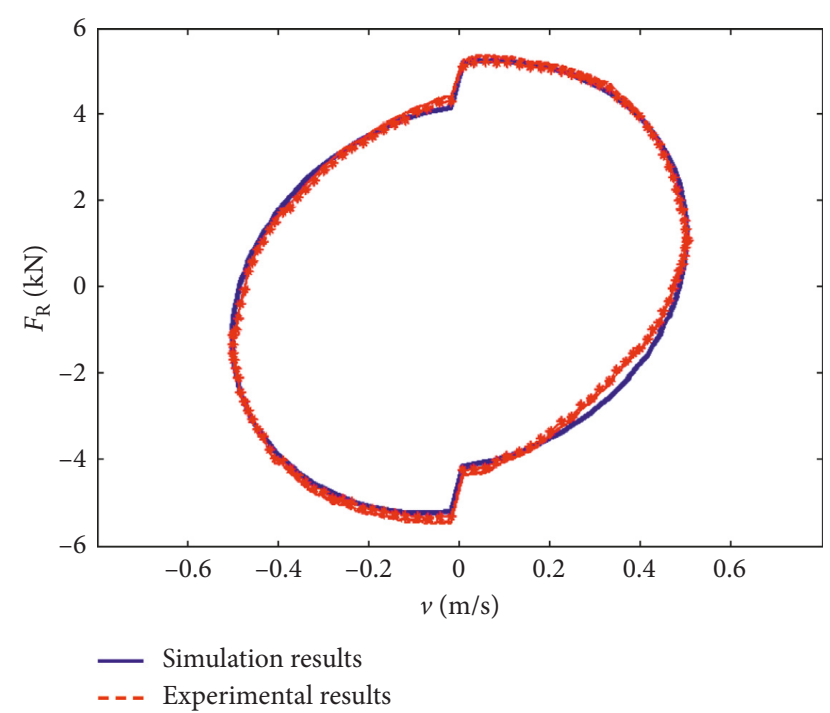

(b)

FIGURE 7: Comparison diagram of the model simulation and experimental results at a frequency of $8 \mathrm{~Hz}$.

\section{Numerical Analysis of Vehicle ISD Suspension}

4.1. Dynamic Modeling of Vehicle ISD Suspension. A basic series layout of a vehicle suspension model [27] involving the nonlinear hydraulic electric inerter is established in Figure 8.

The model can be expressed by the following dynamic equations:

$$
\left\{\begin{array}{l}
m_{\mathrm{s}} \ddot{z}_{\mathrm{s}}+k\left(z_{\mathrm{s}}-z_{\mathrm{u}}\right)+F_{\mathrm{e}}=0, \\
m_{\mathrm{u}} \ddot{z}_{\mathrm{u}}+k_{\mathrm{t}}\left(z_{\mathrm{u}}-z_{\mathrm{r}}\right)-k\left(z_{\mathrm{s}}-z_{\mathrm{u}}\right)-F_{\mathrm{e}}=0, \\
F_{\mathrm{e}}=k_{\mathrm{e}}\left(z_{\mathrm{s}}-z_{\mathrm{b}}\right)+c_{\mathrm{e}}\left(\dot{z}_{\mathrm{s}}-\dot{z}_{\mathrm{b}}\right)+b\left(\ddot{z}_{\mathrm{s}}-\ddot{z}_{\mathrm{b}}\right) \\
\quad+\operatorname{sgn}\left(\dot{z}_{\mathrm{s}}-\dot{z}_{\mathrm{b}}\right)+F_{1}=c\left(\dot{z}_{\mathrm{b}}-\dot{z}_{\mathrm{u}}\right),
\end{array}\right.
$$

where $m_{\mathrm{s}}$ stands for the sprung mass, $m_{\mathrm{u}}$ is the unsprung mass, $k$ represents the stiffness of the main spring, $c$ stands for the damping coefficient of the suspension, $k_{\mathrm{t}}$ is the tire stiffness, $z_{\mathrm{s}}$ represents the sprung mass vertical displacement, $z_{\mathrm{u}}$ is the unsprung mass vertical displacement, $z_{\mathrm{r}}$ is an input signal from a random road, and $z_{\mathrm{b}}$ represents the vertical displacement of the common end of the damper $c$ and the hydraulic electric inerter.

4.2. Design of the Predictive Controller. To improve the performance of vehicle suspension, predictive control is selected to optimize the thrust of the linear motor. The predictive control in this paper is based on a nonlinear model including friction, parasitic damping, and oil elasticity to obtain the minimum performance index by rolling optimization and feedback correction within a given range. A system block diagram of predictive control is shown in Figure 9.

In this paper, the goal of predictive control is to suppress body acceleration and set current as the control quantity. Since formula (8) is a nonlinear model, the optimal quasi-

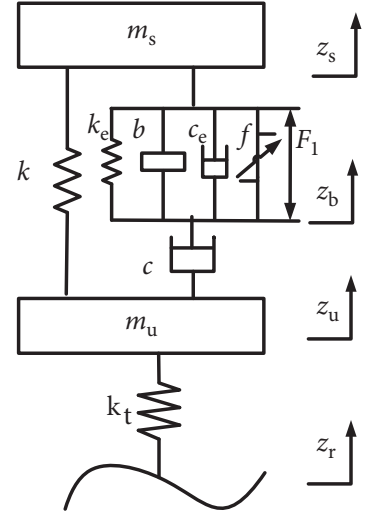

FIGURE 8: Quarter car model of the vehicle suspension involving the hydraulic electric inerter.

linearization method is used to deal with it. Specifically, the output of the nonlinear link is approximated by choosing a linear link. Then, the following difference equation can be obtained:

$$
\left\{\begin{array}{l}
x(k+1)=A x(k)+B_{\mathrm{u}} u(k)+B_{\mathrm{d}} d(k), \\
y_{\mathrm{u}}(k)=C_{\mathrm{u}} x(k)+D_{\mathrm{uu}} u(k)+D_{\mathrm{du}} d(k), \\
y_{\mathrm{m}}(k)=C_{\mathrm{m}} x(k)+D_{\mathrm{dm}} d(k),
\end{array}\right.
$$

where $d(k)$ represents unpredictable interference, $y_{\mathrm{u}}(k)$ represents the immeasurable output, $y_{\mathrm{m}}(k)$ represents the measurable output, $u(k)$ represents the input, and $A, B_{\mathrm{u}}, B_{\mathrm{d}}$, $C_{\mathrm{u}}, C_{\mathrm{m}}, D_{\mathrm{uu}}, D_{\mathrm{du}}$, and $D_{\mathrm{dm}}$ represent the coefficient matrices of each variable.

The primary objective of predictive control in this paper is to suppress body acceleration. Thus, the weights of the body acceleration and suspension working space are set as 0.6 and 0.3 , respectively. 


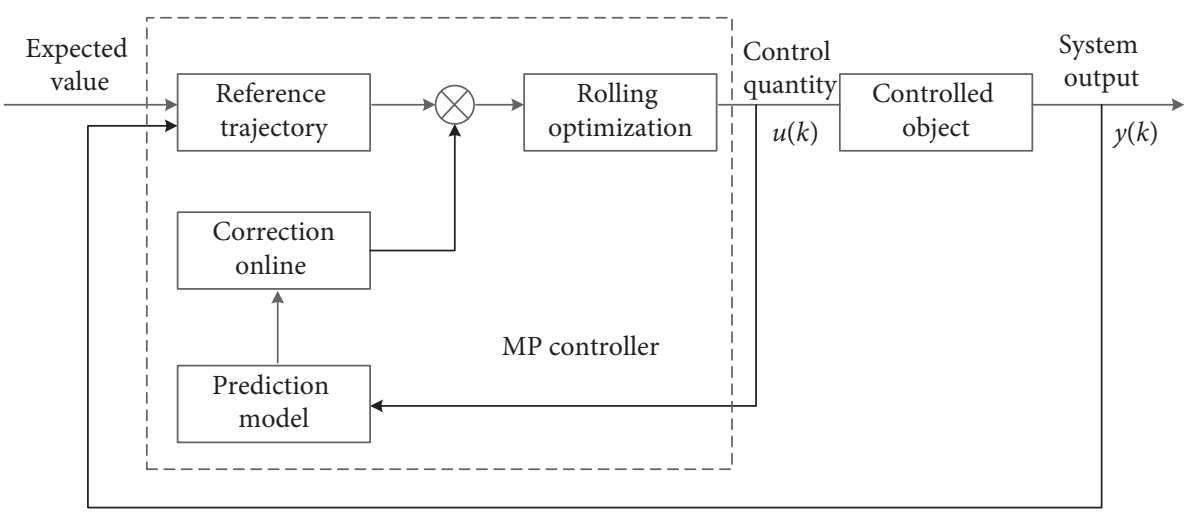

FIGURE 9: Structure diagram of the predictive control system.

Due to external disturbances, nonlinearity of the model, and time-varying state quantities, the results of predictive control alone may not be reliable. To achieve more reliable and stable control, rolling optimization is selected in this paper. Rolling optimization is a method that needs to be carried out in a fixed-length time domain, and the fixed time domain is rolling forward with time. It can compensate the external uncertain disturbance by feedback correction, and the local rolling optimization constraints are shown in Table 5 .

4.3. Performance Simulation of the Suspension. Three performance indices, vehicle body acceleration, suspension working space, and dynamic tire load of hydraulic electric coupling ISD suspension and passive suspension, are compared for vehicles traveling at $20 \mathrm{~m} / \mathrm{s}$ on a road. The relevant parameters used in the simulation are shown in Table 6.

The simulation results are shown in Figure 10.

It can be seen from Figure 10 that compared with passive suspension, the body acceleration, suspension working space, and dynamic tire load of the hydraulic electric coupling ISD suspension with predictive control all have different degrees of reduction. From the perspective of frequency domain, the peak value of hydraulic electric coupling ISD suspension decreases obviously at low frequencies. It is shown that hydraulic electric coupling ISD suspension can effectively suppress body vibration, reduce the collision probability within the suspension system, and limit block and ensure tire grounding.

As shown in Table 7, the RMS values of three performance indices of passive suspension and hydraulic electric coupling ISD suspension at $20 \mathrm{~m} / \mathrm{s}$ are selected to illustrate the performance advantages of hydraulic electric coupling ISD suspension.

From Table 6, it can be seen that compared with passive suspension, the RMS value of the body acceleration with hydraulic electric coupling ISD suspension is reduced by $21 \%$, the RMS value of the suspension working space is reduced by $17 \%$, and the RMS value of the dynamic tire load is reduced by $0.6 \%$. This shows that hydraulic electric coupling ISD suspension with predictive control has better tire grounding and ride comfort at the same time and that
TABLE 5: Rolling optimization constraints.

\begin{tabular}{lc}
\hline Constraints & Constraint range \\
\hline Output constraint & $|a| \leq 5 \mathrm{~m} / \mathrm{s}^{2}$ \\
Body acceleration $a$ & $|l| \leq 8 \mathrm{~cm}$ \\
Suspension working space $l$ & $|I| \leq 5 \mathrm{~A}$ \\
\hline Control constraint & $|\Delta I| \leq 0.5 \mathrm{~A}$ \\
Control quantity $I$ & \\
Control increment $\Delta I$ &
\end{tabular}

TABLE 6: Summary of the simulation parameters.

\begin{tabular}{lc}
\hline Parameters & Values \\
\hline Sprung mass $m_{\mathrm{s}}(\mathrm{kg})$ & 345 \\
Unsprung mass $m_{\mathrm{u}}(\mathrm{kg})$ & 45 \\
Stiffness of the main spring $k\left(\mathrm{~N} \cdot \mathrm{m}^{-1}\right)$ & 22000 \\
Damping coefficient of the suspension $c\left(\mathrm{~N} \cdot \mathrm{S} \cdot \mathrm{m}^{-1}\right)$ & 1500 \\
Inertance $b(\mathrm{~kg})$ & 95 \\
Tire stiffness $k_{t}\left(\mathrm{~N} \cdot \mathrm{m}^{-1}\right)$ & 192000 \\
Road roughness $G_{0}\left(\mathrm{~m}^{3} \cdot \mathrm{cycle}^{-1}\right)$ & $5 \times 10^{-6}$ \\
Speed $u(\mathrm{~m} / \mathrm{s})$ & 20 \\
\hline
\end{tabular}

hydraulic electric coupling ISD suspension has high engineering application value.

\section{Bench Test}

The body acceleration and suspension working space signals in this test are collected by an accelerometer, a displacement sensor, and a data acquisition instrument in real time. The dynamic tire load signal is obtained directly from the force sensor in the single-channel hydraulic servo excitation platform.

The layout of the bench test is shown in Figure 11, which includes a dSPACE, an LMS, a sprung mass, an unsprung mass, a suspension spring, a damper, a hydraulic electric inerter, and a tire model spring.

Figure 12 shows the test performance comparison between hydraulic electric coupling ISD suspension and passive suspension. The RMS values of the test performance are shown in Table 8. 

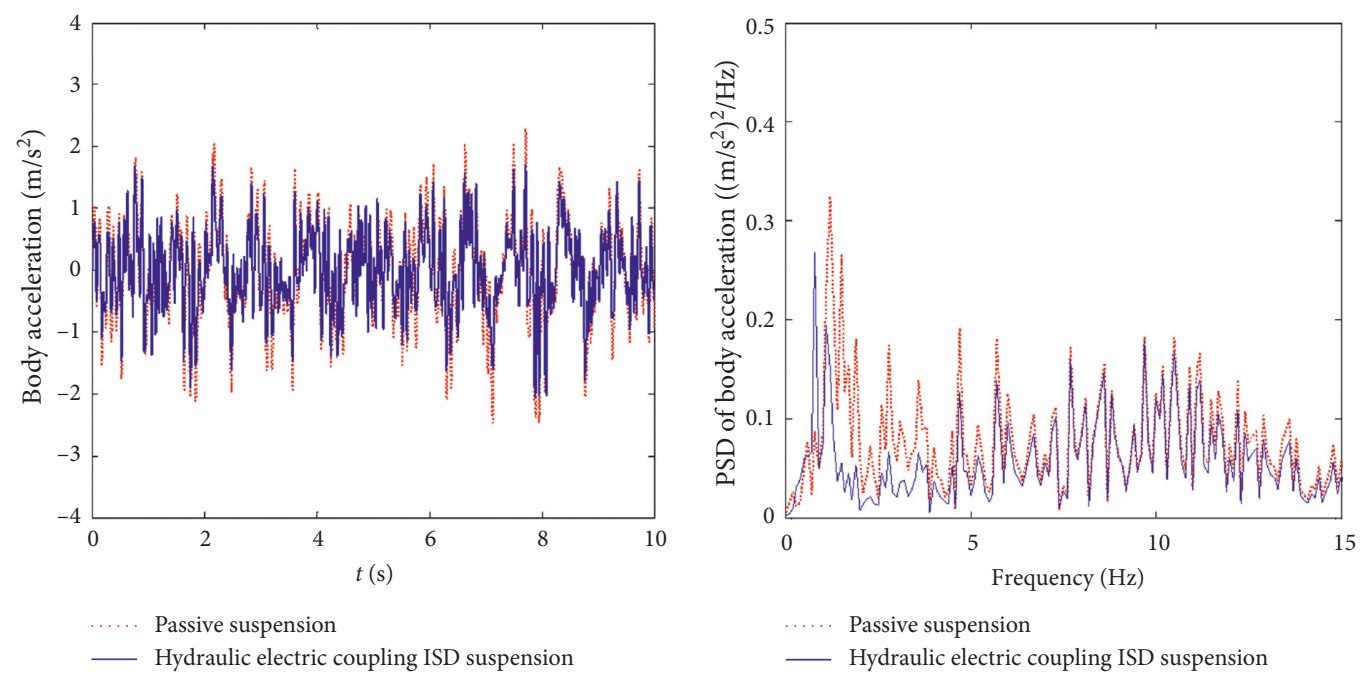

(a)
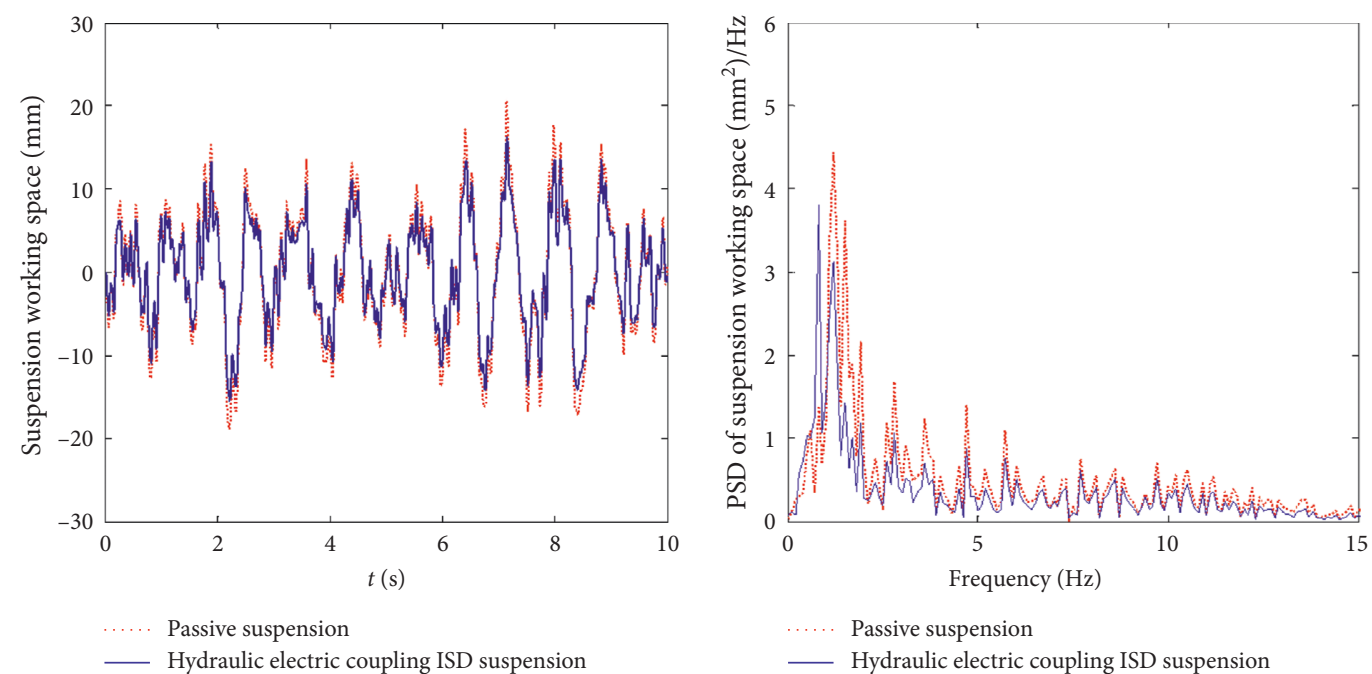

(b)
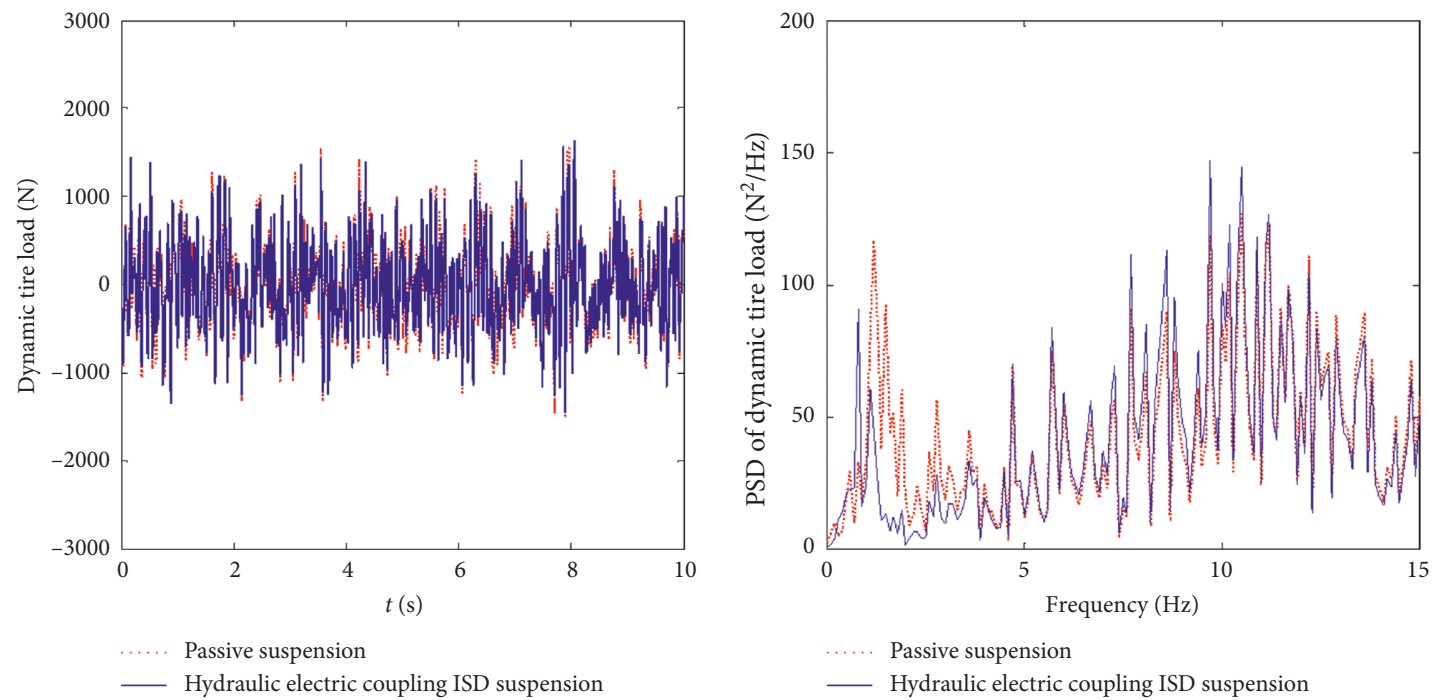

(c)

FIGURE 10: Suspension performance comparison. (a) Body acceleration. (b) Suspension working space. (c) Dynamic tire load. 
TABLE 7: Comparison of the RMS values of the suspension performance.

\begin{tabular}{lcc}
\hline RMS value & Passive suspension & Hydraulic electric coupling ISD suspension \\
\hline Body acceleration $\left(\mathrm{m} / \mathrm{s}^{2}\right)$ & 0.8306 & 0.6565 \\
Suspension working space $(\mathrm{mm})$ & 7.6 & 6.3 \\
Dynamic tire load $(\mathrm{N})$ & 518 & 515 \\
\hline
\end{tabular}

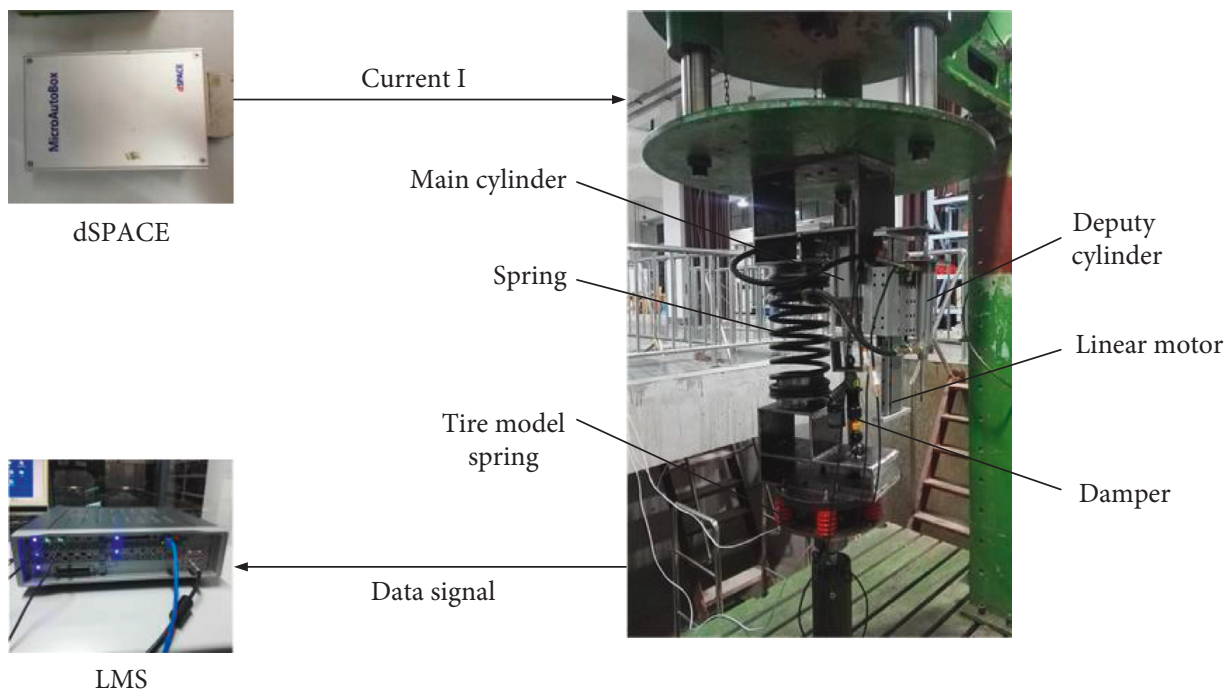

Figure 11: Test layout of the bench.
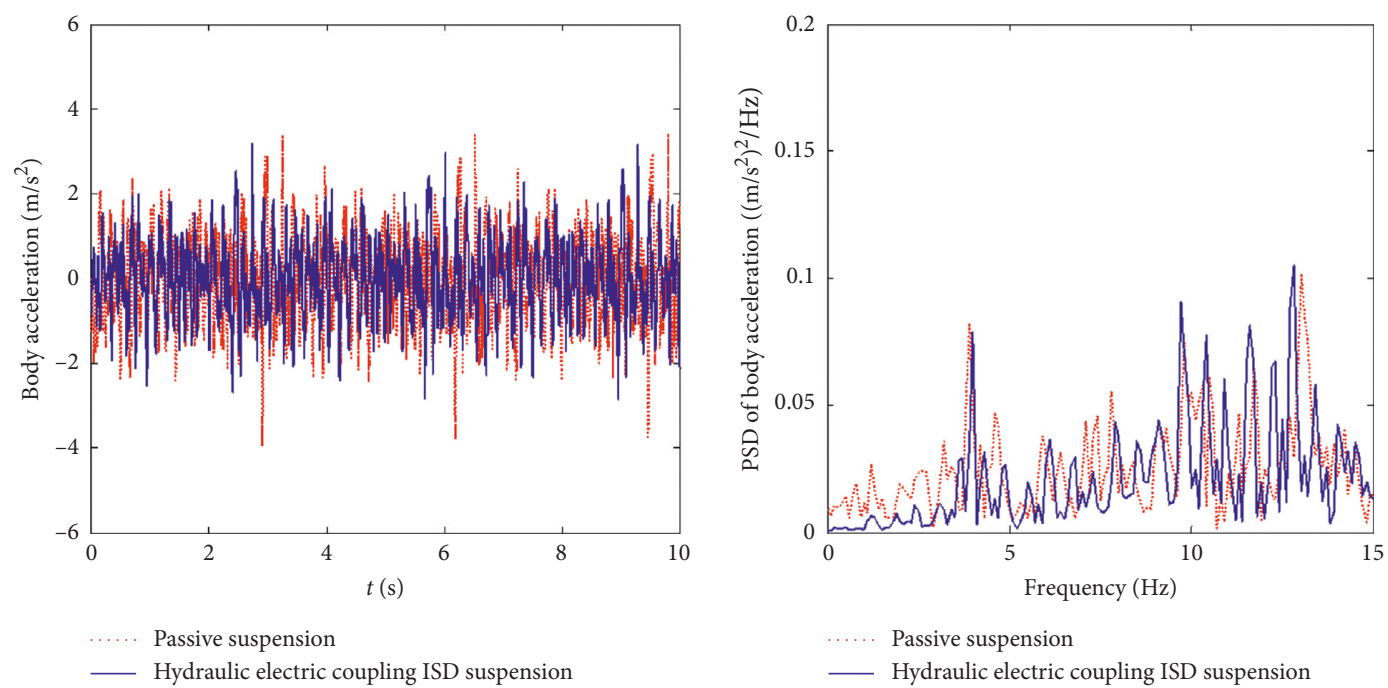

(a)

Figure 12: Continued. 

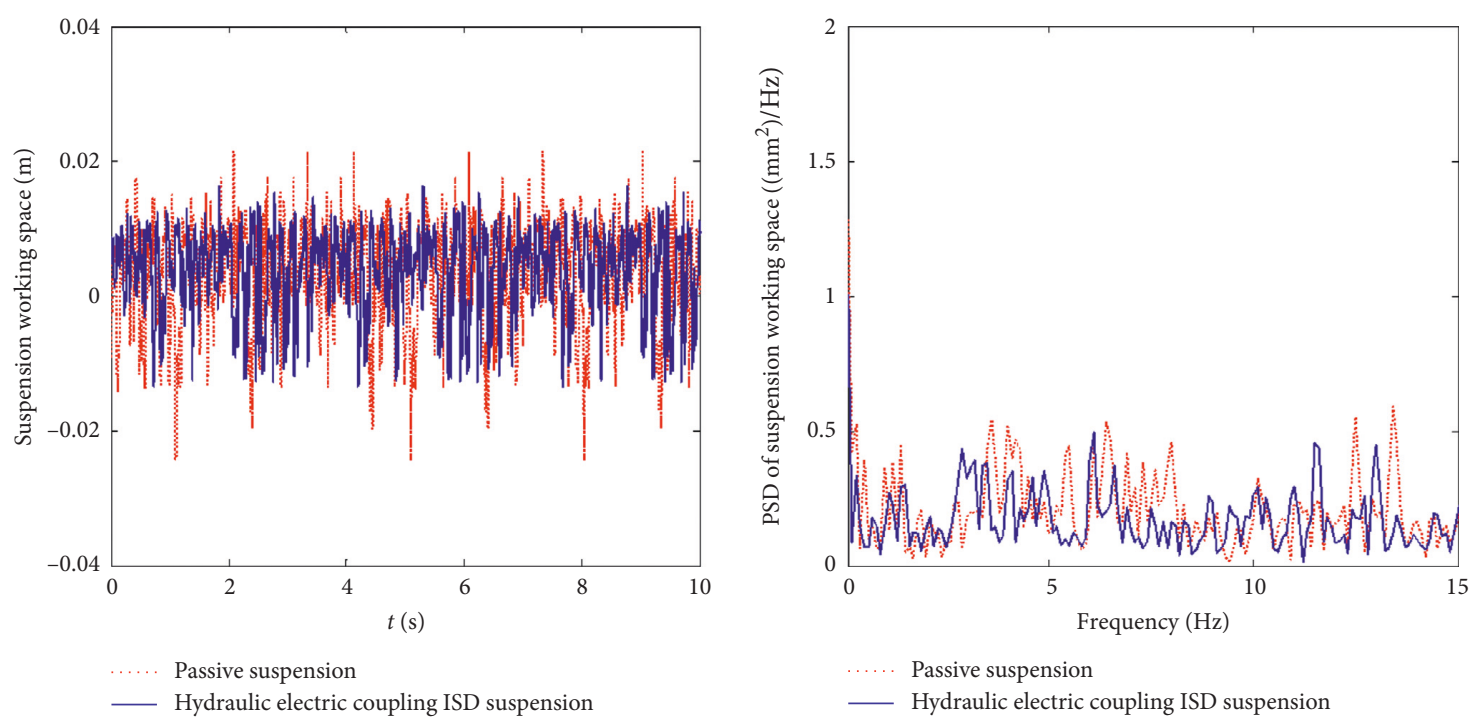

(b)
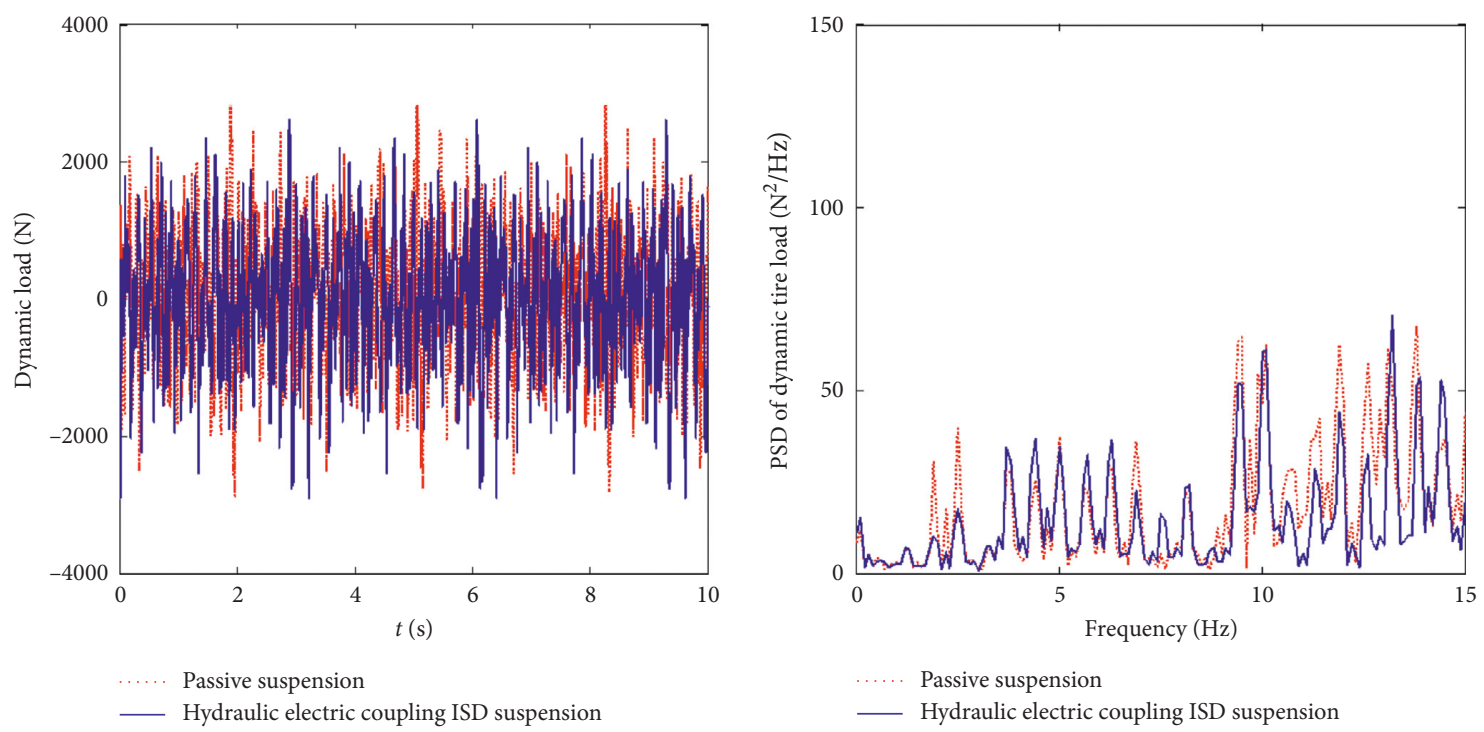

(c)

Figure 12: Test performance comparison. (a) Body acceleration. (b) Suspension working space. (c) Dynamic tire load.

TABLE 8: Comparison of the RMS values of the test performance.

\begin{tabular}{lcc}
\hline RMS value & Passive suspension & Hydraulic electric coupling ISD suspension \\
\hline Body acceleration $\left(\mathrm{m} / \mathrm{s}^{2}\right)$ & 1.0030 & 0.8416 \\
Suspension working space $(\mathrm{mm})$ & 7.9580 & 7.2479 \\
Dynamic tire load $(\mathrm{N})$ & 915.9 & 941.0 \\
\hline
\end{tabular}

From Figure 12 and Table 8, it can be seen that compared with passive suspension, the RMS values of the body acceleration and suspension working space with hydraulic electric coupling ISD suspension and predictive control are significantly reduced by $16.1 \%$ and $8.9 \%$, respectively. The RMS value of the dynamic tire load is not improved obviously because the dynamic tire load in the test is the unmeasurable output of the suspension system, for which there is no predictive control. Similarly, the PSD of body acceleration, suspension working space, and dynamic tire load decreases to varying degrees at low frequencies.

In summary, the performance of the hydraulic electric coupling ISD suspension system with predictive control is obviously improved compared with passive suspension, which verifies the superiority of the performance of 
hydraulic electric coupling ISD suspension and the effectiveness of the predictive controller.

\section{Conclusion}

In this paper, the structural components and working principle of a hydraulic electric inerter were introduced in detail. Based on a force test of the hydraulic electric inerter, nonlinear factors, including friction, the damping force, and the elastic effect, were considered, and the parameters were obtained by means of a system identification method. Then, a dynamic model of the vehicle ISD suspension system incorporating the nonlinear hydraulic electric inerter was established. To improve the vibration isolation performance of vehicle suspension, a predictive controller was designed, and numerical simulations were adopted to verify the effectiveness of the suspension control. Finally, bench tests were carried out, and the results showed that the RMS value of the vehicle body acceleration and the RMS value of the suspension working space were reduced by $16.1 \%$ and $8.9 \%$, respectively.

\section{Data Availability}

The data used to support the findings of the study are available from the corresponding author upon request.

\section{Conflicts of Interest}

The authors declare that there are no conflicts of interest regarding the publication of this manuscript.

\section{Acknowledgments}

This work was supported by the Natural Science Foundation (Grant No. 51705209), the Natural Science Foundation of Jiangsu Province (Grant No. BK20160533), the project funded by China Postdoctoral Science Foundation (Grant No. 2019M651723), the Key Laboratory of Road Vehicle New Technology Application in Jiangsu Province (Grant No. BM20082061510), Key Research and Development Program Projects in Zhenjiang, and the New Energy Vehicle Advantage Discipline Project in Jiangsu University.

\section{References}

[1] E. M. Elbeheiry, D. C. Karnopp, M. E. Elaraby, and A. M. Abdelraaouf, "Advanced ground vehicle suspension systems-a classified bibliography," Vehicle System Dynamics, vol. 24, no. 3, pp. 231-258, 1995.

[2] M. C. Smith, "Synthesis of mechanical networks: the inerter," IEEE Transactions on Automatic Control, vol. 47, no. 10, pp. 1648-1662, 2002.

[3] K. Wang and M. Z. Q. Chen, "Minimal realizations of threeport resistive networks," IEEE Transactions on Circuits and Systems I: Regular Papers, vol. 62, no. 4, pp. 986-994, 2015.

[4] M. Z. Q. Chen, Y. L. Yinlong Hu, C. Y. Guanrong Chen, and G. R. Chen, "Performance benefits of using inerter in semiactive suspensions," IEEE Transactions on Control Systems Technology, vol. 23, no. 4, pp. 1571-1577, 2015.

[5] L. Chen, C. N. Liu, W. Liu, J. M. Nie, Y. J. Shen, and G. T. Chen, "Network synthesis and parameter optimization for vehicle suspension with inerter," Advances in Mechanical Engineering, vol. 8, no. 12, pp. 1-7, 2016.

[6] F.-C. Wang and H.-A. Chan, "Vehicle suspensions with a mechatronic network strut," Vehicle System Dynamics, vol. 49, no. 5, pp. 811-830, 2011.

[7] I. F. Lazar, S. A. Neild, and D. J. Wagg, "Using an inerterbased device for structural vibration suppression," Earthquake Engineering \& Structural Dynamics, vol. 43, no. 8, pp. 1129-1147, 2014.

[8] F.-C. Wang, M.-F. Hong, and C.-W. Chen, "Building suspensions with inerters," Proceedings of the Institution of Mechanical Engineers, Part C: Journal of Mechanical Engineering Science, vol. 224, no. 8, pp. 1605-1616, 2010.

[9] F.-C. Wang, M.-K. Liao, B.-H. Liao, W.-J. Su, and H.-A. Chan, "The performance improvements of train suspension systems with mechanical networks employing inerters," Vehicle System Dynamics, vol. 47, no. 7, pp. 805-830, 2009.

[10] F.-C. Wang and M.-K. Liao, "The lateral stability of train suspension systems employing inerters," Vehicle System Dynamics, vol. 48, no. 5, pp. 619-643, 2010.

[11] Y. Hu, J. Wang, M. Z. Q. Chen, Z. Li, and Y. Sun, "Load mitigation for a barge-type floating offshore wind turbine via inerter-based passive structural control," Engineering Structures, vol. 177, pp. 198-209, 2018.

[12] Y. Wang, R.-C. Wang, and H.-D. Meng, "Analysis and comparison of the dynamic performance of one-stageinerterbased and linear vibration isolators," International Journal of Applied Mechanics, vol. 10, no. 1, article 1850005, 2018.

[13] Y. Hu, M. Z. Q. Chen, and M. C. Smith, "Natural frequency assignment for mass-chain systems with inerters," Mechanical Systems and Signal Processing, vol. 108, pp. 126-139, 2018.

[14] F.-C. Wang and W.-J. Su, "Impact of inerter nonlinearities on vehicle suspension control," Vehicle System Dynamics, vol. 46, no. 7, pp. 575-595, 2008.

[15] M. Z. Q. Chen and M. C. Smith, "Electrical and mechanical passive network synthesis," Lecture Notes in Control \& Information Sciences, vol. 371, pp. 35-50, 2008.

[16] F.-C. Wang, M.-F. Hong, and T.-C. Lin, "Designing and testing a hydraulic inerter," Proceedings of the Institution of Mechanical Engineers, Part C: Journal of Mechanical Engineering Science, vol. 225, no. 1, pp. 66-72, 2011.

[17] D. Li and Y. Z. Liu, "Designing and simulating a mechatronic inerter," Applied Mechanics and Materials, vol. 620, pp. 28-32, 2014.

[18] M. C. Smith and F.-C. Wang, "Performance benefits in passive vehicle suspensions employing inerters," Vehicle System Dynamics, vol. 42, no. 4, pp. 235-257, 2004.

[19] C. Papageorgiou and M. C. Smith, "Positive real synthesis using matrix inequalities for mechanical networks: application to vehicle suspension," IEEE Transactions on Control Systems Technology, vol. 14, no. 3, pp. 423-435, 2006.

[20] Y. Hu, M. Z. Q. Chen, and Z. Shu, "Passive vehicle suspensions employing inerters with multiple performance requirements," Journal of Sound and Vibration, vol. 333, no. 8, pp. 2212-2225, 2014.

[21] Y. Shen, L. Chen, X. Yang, D. Shi, and J. Yang, "Improved design of dynamic vibration absorber by using the inerter and its application in vehicle suspension," Journal of Sound and Vibration, vol. 361, pp. 148-158, 2016.

[22] Y. Hu, M. Z. Q. Chen, S. Xu, and Y. Liu, "Semiactive inerter and its application in adaptive tuned vibration absorbers," IEEE Transactions on Control Systems Technology, vol. 25, no. 1, pp. 294-300, 2017. 
[23] Y. Wang, H. D. Meng, B. Y. Zhang, and R. C. Wang, "Analytical research on the dynamic performance of semi-activeinerterbased vibration isolator with acceleration-velocity-based control strategy," Structural Control and Health Monitoring, vol. 26, no. 4, p. e2336, 2019.

[24] X.-J. Zhang, M. Ahmadian, and K.-H. Guo, "On the benefits of semi-active suspensions with inerters," Shock and Vibration, vol. 19, no. 3, pp. 257-272, 2012.

[25] P. Li, J. Lam, and K. C. Cheung, "Control of vehicle suspension using an adaptive inerter," Proceedings of the Institution of Mechanical Engineers, Part D: Journal of Automobile Engineering, vol. 229, no. 14, pp. 1934-1943, 2015.

[26] M. Z. Q. Chen, Y. Hu, C. Li, and G. Chen, "Semi-active suspension with semi-active inerter and semi-active damper," IFAC Proceedings Volumes, vol. 47, no. 3, pp. 11225-11230, 2014.

[27] Y. J. Shen, L. Chen, Y. L. Liu, and X. L. Zhang, "Influence of fluid inerter nonlinearities on vehicle suspension performance," Advances in Mechanical Engineering, vol. 9, no. 11, pp. 1-10, 2017. 


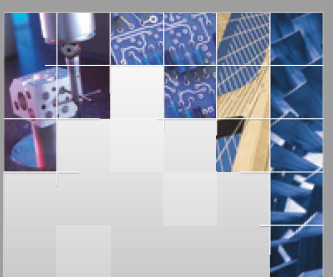

\section{Enfincering}
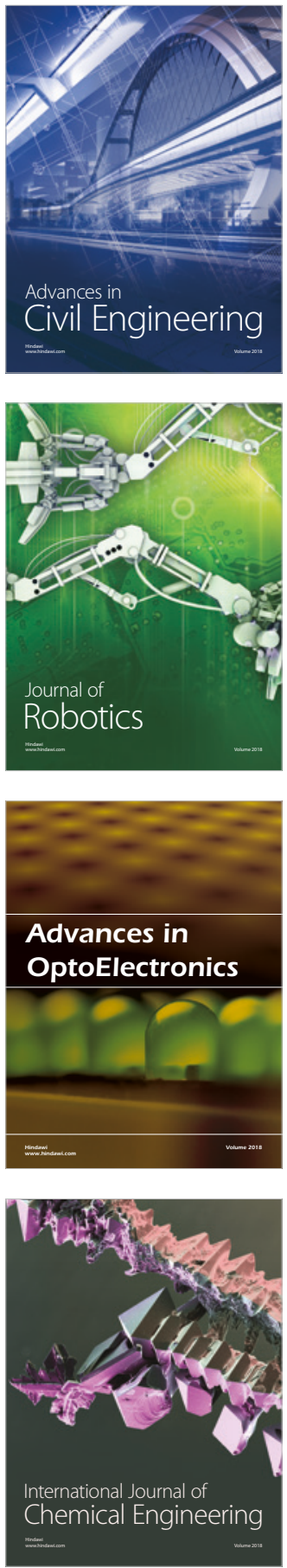

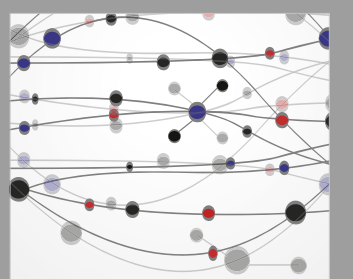

\section{Rotating \\ Machinery}

The Scientific World Journal

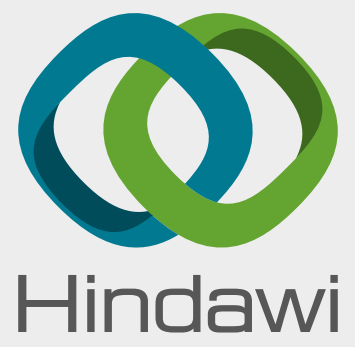

Submit your manuscripts at

www.hindawi.com
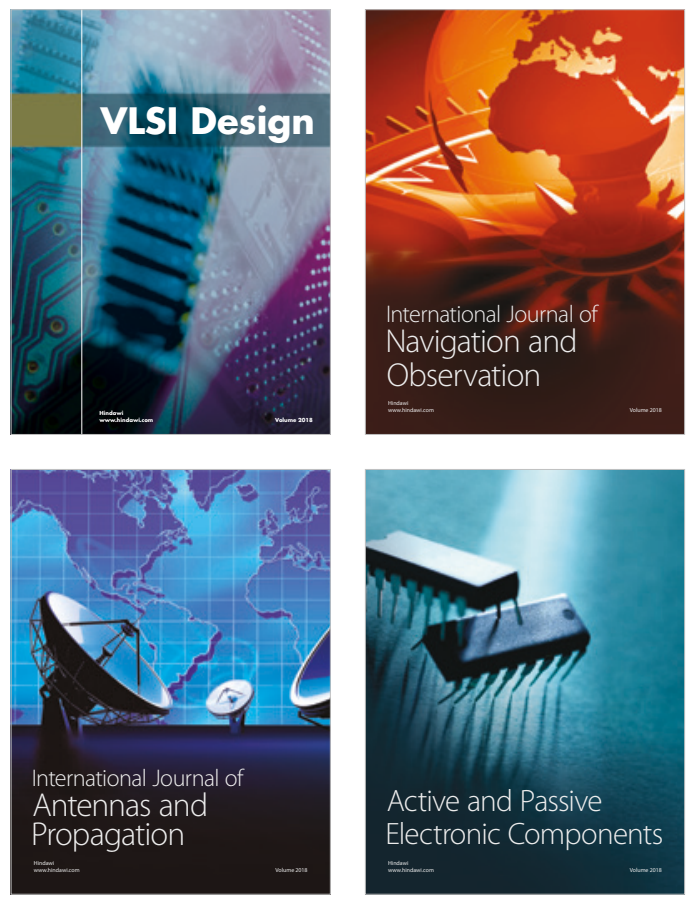
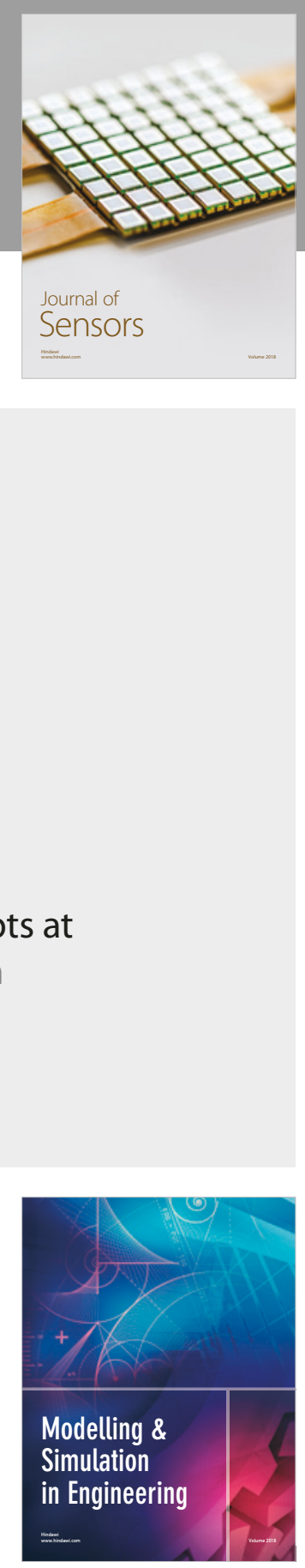

\section{Advances \\ Multimedia}
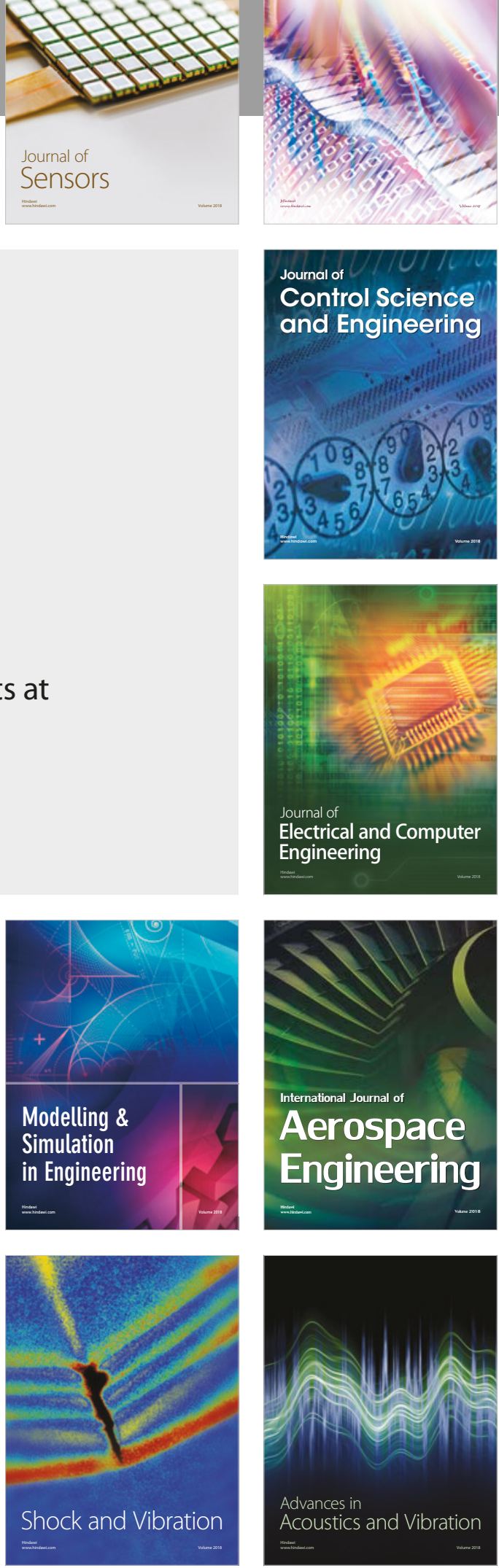